\title{
Venting of Deflagrations in Buildings and Equipment: Universal Correlation
}

\author{
V. MOLKOV, A. KOROLCHENKO and S. ALEXANDROV \\ All-Russian Research Institute for Fire Protection \\ Settlement VNIIPO 12, Balashikha district, Moscow region, 143900 Russia
}

\begin{abstract}
The universal correlation for gaseous deflagration venting in coordinates "dimensionless reduced pressure - turbulent venting parameter" (Molkov, 1995) have been verified on the widened range of experimental data. These included a collection of 39 literature experimental data, processed with proposed earlier theory (Molkov et al., 1981-1995). Correlation covers the most wide range of explosion conditions at initial atmospheric pressure: enclosure volumes up to $8087 \mathrm{~m}^{3}$; vent ratios $F / V^{2 / 3} 0,09-1,23$; initially uncovered and covered vents with release overpressure $0-32 \mathrm{kPa}$ and cover inertia $0-23 \mathrm{~kg} / \mathrm{m}^{2}$; maximum explosion overpressure down to $0,5 \mathrm{kPa}$ and up to $380 \mathrm{kPa}$; most dangerous near stoichiometric air mixtures of natural gas, methane and propane; various shapes of enclosures with ratio of sizes up to 4:1; point, plane and jet ignition; with and without complex obstacles and/or external explosions. It has been proved that the universal correlation is a reliable tool for fire and explosion safety engineering.

It has been shown that best-fit method usually used by researchers for comparison of theoretical and experimental pressure-time profiles should exploit two adjustable parameters - turbulence factor $\chi$ and discharge coefficient $\mu$ for satisfactory results.
\end{abstract}

KEYWORDS: venting of deflagration, reduced overpressure, turbulent venting parameter, correlation, theory and experiment, turbulence factor, discharge coefficient, best-fit method

\section{NOMENCLATURE}

$A$ part of vent cross section area, occupied by burnt gas at a given moment

$A_{s}$ the total area of the sphere available for venting, $\mathrm{m}^{2}$

$a$ vessel radius, $\mathrm{m}$

$c_{u i}$ speed of sound, $\mathrm{m} / \mathrm{s}$ 
$E_{i} \quad$ combustion products expansion coefficient at initial conditions

$F \quad$ vent area, $\mathrm{m}^{2}$

$f_{s} \quad$ surface area of imaginable sphere to which burnt gases may be collected, $\mathrm{m}^{2}$

$f_{t} \quad$ real area of turbulent flame, $\mathrm{m}^{2}$

$M \quad$ molecular mass, $\mathrm{kg} / \mathrm{kmol}$

$n_{b} \quad$ relative mass of burnt gases inside the vessel, $n_{b}=m_{b} / m_{i}$

$n_{u} \quad$ relative mass of unburnt gases inside the vessel, $n_{u}=m_{u} / m_{i}$

$p$ pressure, $\mathrm{Pa}$

$R^{\#} \quad$ dimensionless parameter, characterising discharge

$r$ dimensionless flame radius, $r=r_{b} / a$

$S_{t} \quad$ turbulent burning velocity, $\mathrm{m} / \mathrm{s}$

$S_{u}$ laminar burning velocity, $\mathrm{m} / \mathrm{s}$

$T$ temperature, $\mathrm{K}$

$t$ time, ms

$V \quad$ vessel volume, $\mathrm{m}^{3}$

$W \quad$ venting parameter

$W_{t}$ turbulent venting parameter, $W_{t}=\frac{W}{\chi}=\frac{1}{\left(36 \pi_{0}\right)^{1 / 3} \sqrt{\gamma_{u}}} \frac{\mu F}{V^{2 / 3}} \frac{c_{u i}}{\chi S_{u i}}$

\section{GREEK}

$\gamma \quad$ ratio of specific heats

$\varepsilon \quad$ thermokinetic factor

$\mu \quad$ discharge coefficient

$\pi \quad$ dimensionless pressure, $\pi=p / p_{i}$

$\pi_{0} \quad$ pi number

$\rho \quad$ venting gas density, $\mathrm{kg} / \mathrm{m}^{3}$

$\sigma \quad$ dimensionless venting gas density, $\sigma=\rho / \rho_{i}$

$\tau \quad$ dimensionless time, $\tau=t \cdot \chi S_{u i} / a$

$\chi \quad$ turbulence factor (after vent release for initially covered vents)

$\chi_{0}$ turbulence factor before vent release

\section{Subscripts}

a space into which venting is occur

$b$ burnt gases

$i \quad$ initial state

$m$ maximum value

red reduced overpressure

$u \quad$ unburnt gases

$v \quad$ venting 


\section{INTRODUCTION}

A lot of studies have been made for pressure relief of explosions since investigation of Davy in 1816 as mentioned by Bradley and Mitcheson in their principal paper [1]. In spite of it gaseous explosions continue to destroy domestic and industrial buildings, technological and special equipment, other installations and enclosures until now. Practically all explosions start and develop as deflagrations and only a little part of them transit to detonation mode. Deflagration venting is a more convenient, cost-effective technique in comparison with others: inerting, suppression and containment [2]

To prevent destruction you need to provide building or equipment by adequate venting area. Simple empirical formulas merely based on fitting to concrete set of experimental data were used earlier and are exploited sometimes now for calculating of safe venting area. It was shown by Donat $[3,4]$ that difference in "safe" vent areas determined with use of various empirical formulas may reach ten or even hundred times. Furthermore, it is well established now that physically grounded scaling-up of such results is impossible. Since the work of Munday [5] published in 1963 the detailed models of deflagration venting, based on conservation laws and other physical and chemical relationships, start to appear. Among them the models of Yao et al. [6, 7] 1969-1974, Pasman et al. [8] 1974, Sapko et al. [9] 1976, Bradley and Mitcheson [1] 1978, Korotkikh and Baratov [10] 1978, Crescitelli et al. [11, 12] 1979-1980, Molkov and Nekrasov [13, 14] 1981-1995, Fairweather and Vasey [15] 1982, Swift [16] 1983, Chippett [17] 1984, Epstein and Swift [18] 1986, Orlov [19] 1987, Canu and Rota et al. [20, 21] et al. The main advantage of detailed models over simple empirical formulas is the possibility to calculate dynamics of vented deflagrations (pressure-time profiles) and hence maximum explosion pressure with more reliability in wide range of initial conditions.

\section{SOME PREVIOUS RESULTS AND KEY PROBLEM}

Let us call the dimensionless venting parameter, $\bar{A} / \overline{S_{0}}$. introduced for the first time from the simplified consideration in [1] as Bradley number, where

$\bar{A}=\mu F / A_{S}$ and $\overline{S_{o}}=\frac{S_{u i}}{c_{u i}}\left(\frac{\rho_{u i}}{\rho_{b i}}-1\right)$.

The computer solutions [1] for laminar spherical flame propagation were compared with a lot of experimental data in terms of the suggested parameters: maximum overpressure $\Delta p_{m}$ and Bradley number $\bar{A} / \overline{S_{O}}$ [22]. The scattering between experimental data as well as between experimental data and computer solutions in $\Delta p_{m}-\bar{A} / \overline{S_{o}}$ coordinates reaches sometimes one hundred. It was concluded that the differences between theoretical and experimental data exists due to uncertainty about effects of turbulence and pressure wave generation.

One of the main results of Bradley and Mitcheson's work [1,22] is recommendations for safe values of the dimensionless Bradley number $\bar{A} / \overline{S_{o}}$ in dependence on reduced explosion overpressure $\Delta p_{m}$ for both initially uncovered and covered vents. They have recommended two curves (uncovered and covered vents), which are practically the upper bounds for corresponding processed in [22] experimental data. 
From our detailed theory of deflagration venting $[13,14]$ it follows that venting parameter is equal to

$W=\frac{1}{\left(36 \pi_{0}\right)^{1 / 3} \sqrt{\gamma_{u}}} \frac{\mu F}{V^{2 / 3}} \frac{c_{u i}}{S_{u i}}$

The venting parameter $W$ is very similar to Bradley number $\bar{A} / \overline{S_{o}}$. It is easy to show that the relationship between them is

$W=\frac{E_{i}-1}{\sqrt{\gamma_{u}}} \cdot \bar{A} / \overline{S_{o}}$

and a little difference can be explained as follows. The combustion products expansion coefficient at initial conditions $E_{i}$ is a separate parameter of similarity in our detailed theory governing equations and not coupled together with venting parameter in the same group.

Bradley and Mitcheson fulfilled their calculations for laminar spherical flame propagation that accord to assumption that turbulence factor $\chi=1$. In our works we have supposed that turbulence factor $\chi$ is, in general case of "surface" model of turbulent combustion, the ratio of areas, not burning velocities. It is the ratio of real area of flame front surface to area of imaginable sphere to which the combustion products, being inside the vessel at the same moment, might be collected: $\chi=f_{t} / f_{s}$. It is obvious position because in this case the product $\chi \cdot S_{u}$ will really determine the rate of combustion inside the vessel - with or without spherical symmetry in flame propagation assumption. It is very important note because some researchers continue to use the value of flame acceleration (ratio of flame propagation velocity after and before obstacles), obtained on one part of flame front inside the enclosure like building, to spread it on all parts of flame front. It may lead to violent overestimation of maximum explosion pressure or, that is the same in the inverse problem, the vent area. The reliable values of turbulence factor $\chi$ as the ratio of areas can be obtained only from the comparison of detailed theory and experiments by best-fitting with the use of $\chi$ and $\mu$ as two adjustable parameters, not from cinegrams of flame acceleration at the selected direction.

It has been shown earlier with use of the simple engineering formulas [23], which comprise the ratio of turbulence factor $\chi$ to discharge coefficient $\mu$ as adjustable parameter, and were derived from detailed theory [14], that recommendations of Bradley and Mitcheson [22] in logarithmic coordinates $\Delta p_{m}-W$ coincide with our formulas for subsonic discharge with $\mu=0,6$ when turbulence factor $\chi=2$ for initially uncovered and $\chi=8$ for initially covered vents.

Recommendations [22] were obtained from various experiments fulfilled in practically hollow enclosures of volume up to $200 \mathrm{~m}^{3}$. For these conditions above mentioned values of turbulence factor can be used for safe vent design with good reliability. However, it is well known now that obstacles inside enclosures can generate high level of turbulence during venting of deflagration. In such circumstances recommendations [22] will not work. Indeed, Lee and Guirao have shown in their paper [24], based on Moen et al. experiments, that repeated and even single obstacles can change dramatically maximum explosion pressure. The criticism of such kind must be recognised without any doubts because it is reality. The conclusion is that the turbulent 
combustion of different nature inside the vessel is the key problem, which must be solved as soon as possible to close this day understanding of deflagration venting.

The attempts have been made since Munday [5] to estimate quantitatively the level of turbulence during venting of deflagration with use of detailed models, experiments and best-fit approach. Some of them recommended the values of turbulence factor based on restricted, narrow range of exploited experimental data, for example $[5,7,8,12,13,15]$. The others used the dependence of turbulence factor on flame and vent outflow Reynolds numbers to take into account the changes of $\chi$ during explosion $[16,17,20,21]$ and it is very difficult to estimate average values of $\chi$ from such results. Three years later after the original work of Swift with "elaborate approach" [16] the same group of American researchers Epstein, Swift and Fauske [18] concluded that "it seems best to employ a constant turbulence correction factor and gain the corresponding simplicity, rather than to carry more elaborate equations through a train of numerical computations whose accuracy is also limited to only a narrow range of experimental conditions". It is really great and honest conclusion. After this words there is no needs for various researchers working in this field to compete with others in more "physical" approach until there is no feelings on our "fingers tips" and simple qualitative understanding about influence of deflagration venting conditions on "constant turbulence correction factor".

The outstanding works of Italian researchers [20,21], based on 160 experiments of various authors, don't add simplicity to "fingers tips" understanding of the phenomenon of turbulence generation during venting of deflagration. They exploit only one model from multitude of other possible models to describe turbulence and it is impossible to obtain explicit dependence of turbulence factor on, for example, volume of enclosure or vent ratio from their results.

Furthermore, Zalosh has shown that there is no correlation between $\chi=$ const and $\chi=f\left(\operatorname{Re}_{v}\right)$ approaches until now [25]. He has shown also that there is no clear correlation between values of turbulence factor obtained by different authors. The reasons of it he has assumed in the only significant differences in the formulation of detailed models concern: assumption about the composition of the vented gas; assumed flame geometry; the empirical parameters and correlation to account for turbulence enhanced combustion and flame acceleration induced by flame instabilities.

May be the first attempt to estimate quantitatively the dependence of turbulence factor $\chi$ on explosions conditions, such as volume $V$ and "true" vent ratio $F / V^{2 / 3}$, as well as maximum explosion pressure in closed vessel $\pi_{e}$ and maximum pressure to which the walls of enclosure can to withstand $\pi_{m}$ (or dimensionless reduced explosion overpressure), was undertaken in 1991 [23]. According to this work turbulence factor grows in vessels up to $10 \mathrm{~m}^{3}$ volume proportionally to the vessel volume and the vent ratio, but decreases with increase of permissible explosion pressure. It was very encouraging result, which proved us that detailed theory, with the assumption $\chi=$ const during the explosion, can lead to physically clear understanding of changes in the level of turbulence with changing of explosion initial conditions. We must underline, that best-fit values of $\chi$ were obtained in couple with $\mu$ from the comparison of theoretical pressure-time curves with experimental ones. It is more reliable approach for determination of $\chi$ than its estimation from comparison of maximum explosion pressures only. In the review [23] we processed only own experiments and obtained good correlations. 
In 1995 we elaborated with the use of our detailed theory the experimental data on explosion dynamics of other researchers [14]. The experimental pressure-time curves of Yao [7], Pasman et al. [8], Zalosh [26], Solberg et al. [27], Moen et al. [28] were processed. These experiments were undertaken in a wide range of initial conditions: enclosures of different volume up to 50 $\mathrm{m}^{3}$ and different shape (cub, cylinders up to $4: 1$, rectangular boxes with sizes ratio up to $3: 1$ ); propane and methane were used as fuels with concentrations in the most dangerous near stoichiomertic range; various vent ratios; vent cover release dimensionless pressure from 1 (initially uncovered vents) to 1,32 ; with different location and type (point and planar) of ignition source; with and without internal obstacles; inertial vent covers.

The results were performed in coordinates $\pi_{\text {red }}-W_{t}$, where $\pi_{\text {red }}$ - reduced overpressure according to NFPA 68 guide terminology, $\pi_{r e d}=\Delta p_{m} / p_{i}$, (other terms are permissible like maximum dimensionless explosion overpressure) and $W_{t}$-turbulent venting parameter. It is easy to see that the only principal difference between turbulent venting parameter $W_{t}$ and Bradley number is introduction of turbulence factor $\chi$ as multiplier to burning velocity. However the grand total of this introduction was astonishing: all points from different experiments lied down on the same line. For the first time the universal correlation of different experiments, undertaken in a wide range of initial conditions of vented deflagration, has been obtained [14].

\section{THEORY, EXPERIMENT, REAL ACCIDENTS}

Let us explain briefly the theoretical background of universal correlation appearance. To process experimental data we have used the system of three ordinary differential equations which can be written in dimensionless form as follows

$$
\begin{aligned}
& \frac{d \pi}{d \tau}=\frac{3 \pi Z \pi^{\varepsilon+1 / \gamma_{u}}\left(1-n_{u} \pi^{-1 / \gamma_{u}}\right)^{2 / 3}-\gamma_{b} W_{t}\left[(1-A) R_{u}^{\#}+A R_{b}^{\#}\left(\frac{\pi^{1 / \gamma_{u}}-n_{u}}{n_{b}}\right)\right]}{\pi^{1 / \gamma_{u}}-\frac{\gamma_{u}-\gamma_{b}}{\gamma_{u}} n_{u}}, \\
& \frac{d n_{u}}{d \tau}=-3\left[\pi^{\varepsilon+1 / \gamma_{u}}\left(1-n_{u} \pi^{-1 / \gamma_{u}}\right)^{2 / 3}+(1-A) R_{u}^{\#} W_{t}\right], \\
& \frac{d n_{b}}{d \tau}=3\left[\pi^{\varepsilon+1 / \gamma_{u}}\left(1-n_{u} \pi^{-1 / \gamma_{u}}\right)^{2 / 3}-A R_{b}^{\#} W_{t}\right],
\end{aligned}
$$

where

$$
Z=\gamma_{b}\left[E_{i}-\frac{\gamma_{u}}{\gamma_{b}} \frac{\gamma_{b}-1}{\gamma_{u}-1}\right] \pi^{\left(1-\gamma_{u}\right) / \gamma_{u}}+\frac{\gamma_{b}-\gamma_{u}}{\gamma_{u}-1}
$$

discharge parameter for subsonic and sonic regime is equal respectively

$$
R^{\# \cdot}=\left\{\frac{2 \gamma}{\gamma-1} \pi \sigma\left[\left(\frac{p_{a}}{p_{i} \pi}\right)^{2 / \gamma}-\left(\frac{p_{a}}{p_{i} \pi}\right)^{(\gamma+1) / \gamma}\right]\right\}^{1 / 2},
$$


$R^{\#}=\left[\gamma\left(\frac{2}{\gamma+1}\right)^{\gamma-1} \pi \sigma\right]^{1 / 2}$

and condition for sonic discharge $\pi \geq \frac{p_{a}}{p_{i}}\left(\frac{1+\gamma}{2}\right)^{\frac{\gamma}{\gamma-1}}$.

Dimensionless density for unburnt and burnt gases are equal respectively $\sigma_{u}=\pi^{1 / \gamma_{u}}$ and $<\sigma_{b}>=n_{b} \sigma_{u} /\left(\sigma_{u}-n_{u}\right)$.

It is easy to see that for the same values of $E_{i}, \gamma_{u}, \gamma_{b}$, ratios $p_{a} / p_{i}$ and $p_{v} / p_{i}$, and assumptions abcut discharge model $(A)$ the theoretical dimensionless pressure-time history and hence dimensionless maximum explosion overpressure will depend only from the turbulent venting parameter $W_{t}$. Whereas the value of $W_{t}$ depends on the only unknown a priori ratio $\chi / \mu$, the dimensionless time $\tau$ depends on the unknown turbulence factor $\chi$ only. It means that during best-fitting procedure the theoretical value of the second pressure peak (for initially covered vents) or the single first peak (for initially uncovered vents) depends on the ratio $\chi / \mu$ only, whereas the theoretical real time of peak attainment is determined by value of $\chi$.

We can conclude from it that turbulence factor $\chi$ can be estimated from the time of achievement of maximum pressure and then by discharge coefficient adjusting we could obtain coincidence of theoretical and experimental pressure peaks. Because of possibility of implicit influence of $\mu$ on combustion time through the mass of vented unburnt gas one could need some iterations of this procedure. It is obvious that determined from best-fit procedure couple of values $\chi$ and $\mu$ is unique. No other couple of $\chi$ and $\mu$ can give the same best-fit theoretical curve.

The main difference of our approach from others is the use of two adjustable parameters during best-fitting procedure $-\chi$ and $\mu$, not only $\chi$. Practically all researches use a priori values of discharge coefficient. Usually it lies in the range between 0,6 and 1 . From our point of view it is the reason why some investigators were impossible to achieve satisfactory fitting between their theoretical and experimental pressure-time records. "Unusual" values of discharge coefficient for $\mu>1$ in our studies can be explained as follows. Standard orifice equations, used by all researches to model venting, were obtained from the law of energy conservation with the assumption that kinetic energy of outflowing gas is equal to zero before orifice, that is right for relatively little holes in the vessel. In the case of deflagration venting the velocity of gases before the vent of relatively large size can be very high comparable with gas velocity after the vent, especially if there is turbulent combustion inside. To compensate the deviation of real gas discharge during venting of deflagration from ideal situation assumed by standard orifice equations the discharge coefficient can vary during best-fitting in relatively wide range of values. Moreover, as we mentioned above and showed in [23] the value of $\mu$ influences mainly, during its adjustment, the value of the maximum explosion pressure. Hence, larger values of $\mu$ may compensate the unaccounting of energy losses in the theory also.

Crescitelli et al. [12] the only known for us group which has determined the values of "modified turbulence factor" $\chi^{\prime}=\chi / \mu$ from best-fitting of their theoretical and experimental [36] maxi- 


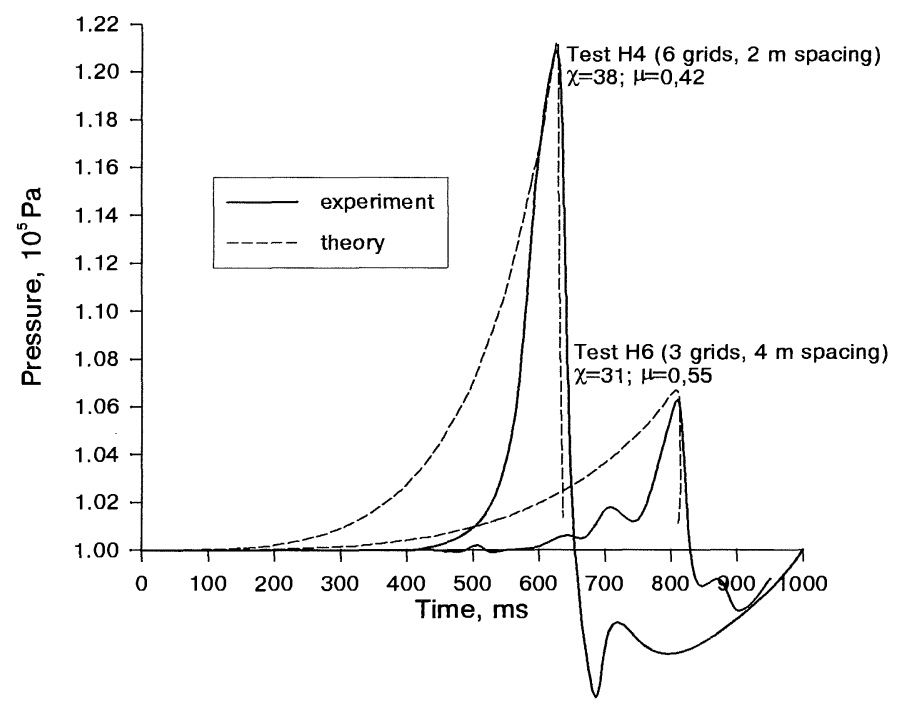

FIGURE 1. Dynamics of $9,6 \%$ natural gas in air explosion in $4000 \mathrm{~m}^{3}$ enclosure with $563 \mathrm{~m}^{2}$ vent area and complex obstacles, which consist of number of grids with determined intergrid spacing. Each grid composed from 10 horizontal pipes of $0,315 \mathrm{~m}$ diameter with blockage ratio $40 \%$. Initially uncovered vent. Point ignition source. Discharge model $A=1$. Initial data for theoretical curves: $S_{u i}=0,37 \mathrm{~m} / \mathrm{s} ; \gamma_{u}=1,39 ; \gamma_{b}=1,25 ; E_{i}=7,44 ; \varepsilon=0,3 ; M=27,6$.

mum explosion pressures. Unfortunately, they didn't estimate values of $\mu$ because of absence of pressure-time traces in Harris and Briscoe's paper [36].

In our previous work [14] we have shown satisfactory fitness of our best-fit theoretical and experimental pressure-time curves from [7, 8, 26-28]. In this paper we are presenting results obtained in [29] during processing Harrison and Eyre's experiments [30, 31] in $4000 \mathrm{~m}^{3}$ confined space with high vent ratio, with and without obstacles, with point ignition and jet ignition. In particular, there are examples of calculated and experimental explosion dynamics curves for tests $\mathrm{H} 4$ and $\mathrm{H} 6$ from [31] on Fig.1. VNIIPO experiments in $10 \mathrm{~m}^{3}$ cylinder with $1,7 \times 0,8 \mathrm{~m}$ vent on $4,05 \%$ propane-air mixtures and various numbers of different grids inside were processed in [32]. Some pressure-time curves from [32] are presented on Fig.2.

Until now 39 explosions were processed. All new data from $[29,32]$ and earlier data from [7, 8, 26-28] are collected and presented on Fig.3. It is obvious that the correlation is really universal. Moreover, the data from our recent work [33] obtained from interpretation of real explosions in domestic structures at Ronan Point (UK) [34] and industrial building at one of Monsanto's plant (USA) [35] are also there on the same correlation. In contrast to Canu et al. [20] our approach permit correct, relatively accurate predictions for low-strength enclosures also. Coefficient of correction determination is 0,96 . Residual mean square is 0,102 .

Let us explain about one experimental point above the correlation line. It accord to the case when the first pressure peak is bigger than the second one, for example if vent release pressure 


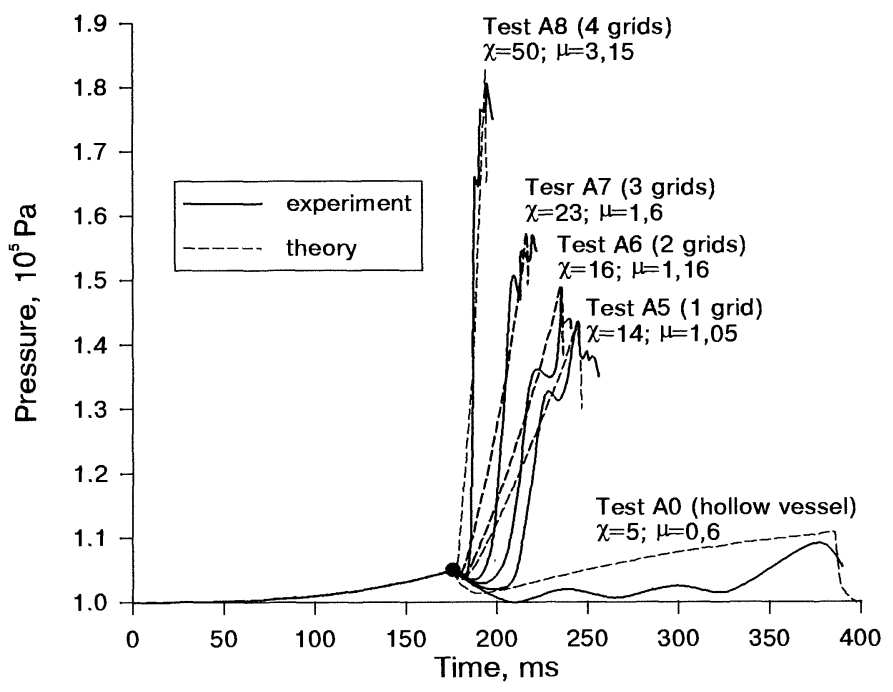

FIGURE 2. Dynamics of $4,05 \%$ propane in air explosion in $11 \mathrm{~m}^{3}$ enclosure with $1,7 \times 0,8 \mathrm{~m}$ vent and different number of metal grids with intergrid spacing $0,1 \mathrm{~m}$. Each grid composed from horizontal and vertical $0,018 \mathrm{~m}$ diameter rods and $0,125 \mathrm{~m}$ mesh size. Vent release overpressure is $5 \mathrm{kPa}$. Point ignition source at rare side. Discharge model $A=r^{2}$. Data for theoretical curves: $\chi_{0} \cdot S_{u i}=0,335 \mathrm{~m} / \mathrm{s} ; \gamma_{u}=1,365 ; \gamma_{b}=1,25 ; E_{i}=7,9 ; \varepsilon=0,31 ; M=29,5$.

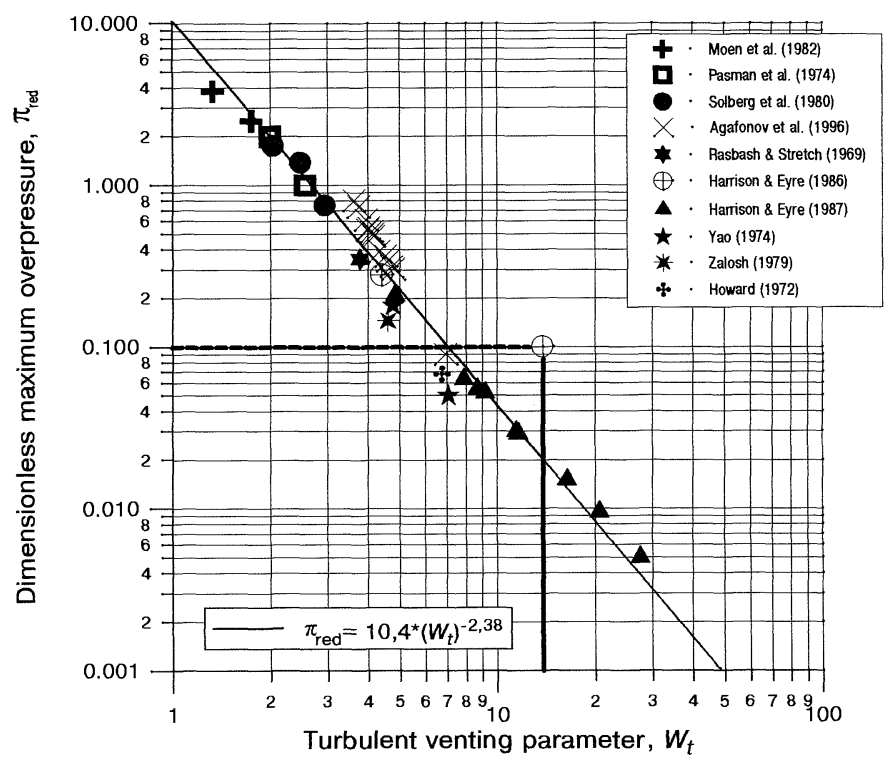

FIGURE 3. Universal correlation. 
is relatively high and vent area is sufficiently large. For light vent covers the first pressure peak is equal to the vent release pressure. Hence, the correlation can be used also for the determination of upper bound for the vent release pressure. So, for given turbulent venting parameter $W_{t}$ this pressure can not be upper the correlation line. Otherwise the maximum explosion pressure will be equal to vent release pressure. This aspect is important in some applications where relatively high-strength vent covers are needed.

\section{CONCLUSIONS}

Universal correlation for vented gaseous deflagrations obtained for the first time in [14] in coordinates $\pi_{\text {red }}-W_{t}$ verified here on widened range of experiments with volumes up to $8087 \mathrm{~m}^{3}$ with and without obstacles, as well as for point and jet ignition. It is correct for high-strength equipment and for low-strength enclosures like buildings. Correlation has practical significance, for example, for hazard appraisal of onshore and offshore modules whose module volumes may be as great as $10000 \mathrm{~m}^{3}$, and can serve as reliable tool for fire and explosion safety engineering. Moreover, the presumption exists that future data on venting of deflagrations will also obey this correlation. The existence of the universal correlation proves the adequacy of proposed theory to experiment and practice as well as confirms the soundness of stated approach to the problem of deflagration venting.

Turbulent combustion coupled with gasdynamics of venting is the key problem of deflagration venting. It has been shown that satisfactory best-fitting of theoretical pressure-time profiles to experimental ones can be achieved in wide range of conditions only with two adjustable parameters - turbulence factor $\chi$ and discharge coefficient $\mu$.

Maximum explosion pressure depends mainly on turbulent venting parameter, in which only the ratio $\chi / \mu$ is not determined today a priori. Conclusions about changes of $\chi / \mu$ with alteration of explosions conditions can be made from our present and previous works. Presupposition exists that the scaling-up problem will be overcome with stated approach. Because of the limited paper length it will be the subject of other studies.

\section{REFERENCES}

1. Bradley D., Mitcheson A., "The Venting of Gaseous Explosions in Spherical Vessels. I - Theory", Combustion and Flame, 32:3, 221-236, 1978a.

2. Swift I., Epstein M., "Performance of Low-Pressure Explosion Vents", Plant/Operations Progress, 6:2, 98-105, 1987.

3. Donat C., "Release of the Pressure of an Explosion with Rupture Discs and Explosion Values", Paper presented at Achema 73 (Second Symposium on the Prevention of Occupational Risks in the Chemical Industry), Frankfurt am Main, West Germany, 1973.

4. Howard W.B., Russell W.W., "Procedure for Designing Gas Combustion Venting Systems", Fifth Symposium on Chemical Process Hazard, I. Chem. E. Symposium Series No. 39a, pp.179-195, 1974.

5. Munday G., "The Calculation of Venting Areas for Pressure Relief of Explosions in Vessels", Second Symposium on Chemical Process Hazards, INSTN CHEM ENGRS, pp.46-54, 1963. 
6. Yao C., deRis J., Bajapi S.N., Buckley J.D., "Evaluation of Protection from Explosion Overpressure in AEC Gloveboxes". - Prepared for USAEC Chi. Oper. Ofc., Argonne, Ill. Dec. 1969. AEC Contract No. AT(11-1)-1392, FMRC Serial No. 16215.1, RC69-T23, 1969.

7. Yao C., "Explosion Venting of Low-Strength Equipment and Structures",_Loss Prevention, 8, 1-9, 1974. (Yao C., "Explosion Venting of Low-Strength Equipment and Structures", Factory Mutual Research Corporation, Norwood, Mass. 02062, 53 p., 1973).

8. Pasman H.J., Groothuisen Th.M., Gooijer P.H., "Design of Pressure Relief Vents", in Loss Prevention and Safety Promotion in the Process Industries, ed. Buschman C.H., pp.185-189, New-York, 1974.

9. Sapko M.J., Furno A.L., Kuchta J.M., "Flame and Pressure Development of Large-Scale $\mathrm{CH}_{4}-\mathrm{Air}-\mathrm{N}_{2}$ Explosions (Buoyancy Effects and Venting Requirements)", Report of Investigation/ US Bureau of Mines, RI 8176, Wash., 32 p., 1976.

10. Korotkikh N.I., Baratov A.N., "Calculation of vent ratio from the undistruction condition for rooms when gaseous explosions", in Goryuchest veshchestv i khimicheskie sredstva pozharotusheniya, 5, 3-15, 1978 (in Russian).

11. Crescitelli S., Russo G., Tufano V., "Analysis and Design of Venting Systems: A Simplified Approach", J. Occup. Accid., 2, 125-133, 1979.

12. Crescitelli S., Russo G., Tufano V., "Mathematical Modelling of Relief Venting of Gas Explosions: Theory and Experiments", in 3rd International Symposium on Loss Prevention and Safety Promotion in Process Industries. Basel, 3, 16/1 187- 16/1197, 1980.

13. Molkov V.V., Nekrasov V.P., "Gas Combustion Dynamics in a Constant Volume Vented Vessel", Physics of Combustion and Explosion, 17, 17-24, 1981 (in Russian, translated into English in "Combustion, Explosion and Shock Waves" journal).

14. Molkov V.V., "Theoretical Generalization of International Experimental Data on Vented Explosion Dynamics", in Proceedings of the First International Seminar on Fire-and-Explosion Hazard of Substances and Venting of Deflagrations (17-21 July 1995, Moscow - Russia), pp.166-181, 1995.

15. Fairweather M., Vasey M.W., "A Mathematical Model for the Prediction of Overpressures Generated in Totally Confined and Vented Explosions", in Nineteenth Symposium (International) on Combustion, The Combustion Institute, pp.645-653, 1982.

16. Swift I., "Gaseous Combustion Venting - A Simplified Approach", in 4th International Symposium on Loss Prevention and Safety Promotion in the Process Industries, The Institution of Chemical Engineers symposium series no.82, Harrogate, England, 82, pp.F21-F37, 1983.

17. Chippett S., "Modeling of Vented Deflagrations", Combustion and Flame, 55, 127-140, 1984.

18. Epstein M., Swift I., Fauske H.K., "Estimation of Peak Pressure for Sonic-Vented Hydrocarbon Explosions in Spherical Vessels", Combustion and Flame, 66:1, 1-8, 1986.

19. Orlov G.G., Venting constractions for explosion protection of industrial buildings, Srtoiizdat, Moscow, 200 p., 1987 (in Russian).

20. Canu P., Rota R., Carra S., Morbidelli M., "Vented Gas Deflagrations A Detailed Mathematical Model Tuned on a Large Set of Experimental Data", Combustion and Flame, 80, 49-64, 1990.

21. Rota R., Canu P., Carra S., Morbidelli M., "Vented Gas Deflagrations A Simplified Approach", Combustion and Flame, 85, 319-330, 1991.

22. Bradley D., Mitcheson A., "The Venting of Gaseous Explosions in Spherical Vessels. II - Theory and Experiment", Combustion and Flame, 32:3, 237-255, 1978b. 
23. Molkov V.V., Baratov A.N., Korolchenko A.Y., " Dynamics of Gas Explosions in Vented Vessels: A Critical Review and Progress", in Progress in Astronautics and Aeronautics, Volume 154 "Dynamics aspects of Explosion Phenomena" / Proceedings of the 13th International Colloquium on Dynamics of Explosions and Reactive Systems (Nagoya - Japan, 1991), 1993, pp.117-131, 1991.

24. Lee J.H.S., Guirao C.M., "Pressure Development in Closed and Vented Vessels", Plant/Operations Progress, 1:2, 75-85, 1982.

25. Zalosh R.G., "Review of Gas Deflagration Venting Models", in Proceedings of the First International Seminar on Fire-and-Explosion Hazard of Substances and Venting of Deflagrations (17-21 July 1995, Moscow - Russia), pp.79-87, 1995.

26. Zalosh R.G., " Gas Explosion Tests in Room-Size Vented Enclosures, Loss Prevention, 13, p.98, 1979.

27. Solberg D.M., Pappas J.A., Skramstad E., "Experimental Investigations on Flame Acceleration and Pressure Rise Phenomena in Large Scale Vented Gas Explosions", in 3rd International Symposium on Loss Prevention and Safety Promotion in Process Industries, Basel, 3, 16/1295-16/1303, 1980.

28. Moen I.0., Lee J.H.S., Hjertager B.H., Fuhre K., Eckhoff R.K., "Pressure Development Due to Turbulent Flame Propagation in Large-Scale Methane-Air Explosion", Combustion and Flame, 47:1, 31-52, 1982.

29. Molkov V.V., Alexandrov S.V., "Turbulent combustion during venting of deflagration in a very large confined spaces with complex obstacles and different types of ignition", Fire and Explosion Safety, 4:1, 3-8, 1996 (in Russian).

30. Harrison A.J., Eyre J.A., "Vapour Cloud Explosions - The Effect of Obstacles and Jet Ignition on the Combustion of Gas Clouds", in Proceedings of the Fifth International Symposium on Loss Prevention and Safety Promotion in the Process Industries (15-19 September 1986, Cannes, France), Published: Societe de Chimie Industrielle, Paris. 1986, 1, pp.38-41, 1986.

31. Harrison A.J., Eyre J.A., "The Effect of Obstacle Arrays on the Combustion of Large Premixed Gas/Air Clouds", Combustion Science and Technology, 52, No.1-3, 121-137, 1987.

32. Molkov V.V., Agafonov V.V., Alexandrov S.V., "Venting of Deflagrations in Large Vessel with Obstacles", Physics of Combustion and Explosion, 1996 (in printing, in Russian).

33. Molkov V.V., " Explosions in Buildings: Modeling and Interpretation of Real Accidents". - Presented at the First European Symposium on Fire Safety Science (21-23 August 1995, Zurich - Switzerland), 1995, The Book of Abstracts, pp.45-46 (in printing in "Fire Safety Journal").

34. Rasbash D. J., Stretch K. L., "Explosions in Domestic Structures", Structural Engineer, 47, 403-411, 1969.

35. Howard W.N., "Interpretation of a Building Explosion Accident", Loss Prevention, 6 , 68-73, 1972.

36. Harris G.F.P., Briscoe P.G., "The Venting of Pentane Vapor-Air Explosions in a Large Vessel", Combustion and Flame, 11:3, 329-338, 1967. 